3-19-2021

\title{
Using evidence to advocate for the professional growth of community health workers in Bangladesh
}

Frontline Health Project

Follow this and additional works at: https://knowledgecommons.popcouncil.org/departments_sbsr-rh How does access to this work benefit you? Let us know!

\section{Recommended Citation}

Frontline Health Project. 2021. "Using evidence to advocate for the professional growth of community health workers in Bangladesh," Results brief. Washington, DC: Population Council. 


\section{USING EVIDENCE TO ADVOCATE FOR THE PROFESSIONAL GROWTH OF COMMUNITY HEALTH WORKERS IN BANGLADESH}

\section{INTRODUCTION}

In many low-and-middle-income countries (LMICs), community health workers (CHWs) are the only link to essential health services for millions of people. In Bangladesh, a country with 0.6 physicians and 0.4 nurses and midwives per 1,000 people (1) - far below the World Health Organization's (WHO) recommendations (2) - CHWs are critical providers of health information and services.

Bangladesh's approximately 185,000 active CHWs are employed both by the government and non-governmental organizations (NGOs). The NGO BRAC employs an estimated 100,000 volunteer CHWs, known locally as Shasthya Shebikas. Bangladesh's Ministry of Health and Family Welfare (MoHFW) employs approximately 47,089 CHWs in several cadres-primarily as Family Welfare Assistants (FWAs), Health Assistants (HAs), and Community Health Care Providers (CHCPs) - with many posts vacant (3).

CHCPs do not visit local households; rather, they provide a range of preventive and primary care six days a week at community clinics (CCs) (3).

FWAs and HAs - the focus of this brief - divide their time between households and CCs. Formally introduced in the 1970s, FWAs counsel individual clients and couples and educate couples/ households on family planning (FP) and maternal health (4). They provide contraceptive pills, condoms, as well as the second dose of injectable contraception, in addition to identifying and registering pregnant women for antenatal services. FWAs spend two of their work days every week organizing and managing satellite events at Union Health and Family Welfare Centres (UHFWCs), and their remaining three days based at CCs (3). HAs, based at CCs three days a week, organize and provide immunization as well as conduct disease surveillance in their communities.

In recent years, the MoHFW inaugurated two additional cadres of paid auxiliary CHWs: Multi-Purpose Health Volunteers (MHVs) and Paid Peer Volunteers (PPVs). MHVs live and work in CC service areas, supporting disease prevention, health standards improvement, rehabilitation, and emergency assistance. PPVs provide health information to adolescents, conduct FP visits, provide referrals for long-acting reversible contraceptives (LARCs) and permanent methods, and fill FWA vacancies (3).

\section{KEY FINDINGS}

1. In Bangladesh, FWAs and HAs are highly valued and trusted CHW cadres, yet they face challenges that affect their motivation and performance.

2. FWAs and HAs are dissatisfied with their pay scales and lack opportunities to utilize their skills and knowledge in higher positions.

3. Equalizing the pay scales between FWAs and HAs as well as providing promotion and training opportunities can improve their motivation and performance.
This Results Brief presents key findings from the Frontline Health project's study in Bangladesh $(5,6)$. This study is part of a larger portfolio of work by the Frontline Health project, which seeks to advance community health systems with metrics, monitoring, and learning to improve CHW programs' efficiency and performance (7).

Despite significant challenges, Bangladesh's CHWs are highly trusted, respected, and valued in their communities as essential frontline health workers and client confidantes $(5,6)$. This brief reveals that inequitable compensation in comparison with client workloads, combined with lack of opportunities for career advancement and necessary training, have led to dissatisfaction among $\mathrm{CHWs}$ and decreased their motivation to progress or excel in their duties, which ultimately influences client quality of care and community health outcomes (5). The evidence in this Frontline Health brief indicates that guaranteeing equitable compensation and standardized systems for promotion as well as training within Bangladesh's government-led $\mathrm{CHW}$ programs has the potential to increase CHWs' motivation, satisfaction, and ultimately, performance with clients and within their communities.

\footnotetext{
The information presented in this brief is based on key findings from a survey of Family Welfare Assistants (FWAs) ( $n=76)$, a client survey ( $n=1,017)$, three focus group discussions (FGDs) with Health Assistants (HAs), and in-depth interviews (IDIs) with Family Welfare Assistants ( $n=10$ ), their supervisors $(n=5)$, and program managers $(n=5)$. Baseline data collection occurred from November 2019 through January 2020 in the Keraniganj upazila (e.g., sub-district) of Dhaka $(5,6)$.
} 


\section{RESULTS}

Our data indicate that FWAs face numerous challenges that affect their motivation and job performance. Despite these challenges, FWAs maintain trusting relationships with their clients and constituent communities $(5,6)$.

\section{Challenges articulated by FWAs and HAs}

FWAs feel dissatisfied with their pay scale in comparison with HAs, a CHW cadre of similar workload. Both cadres lack opportunities for promotion and training (6).

\section{Inequitable pay scales for similar functions}

FWA motivation scores suggest that FWAs generally feel valued, respected, and well supervised (6). Quantitative data indicate $100 \%$ of FWAs surveyed were satisfied with their long-term job security (Table 1). Nearly $20 \%$ of FWAs reported working 5-10 years in the same position, while $76 \%$ had been in the same position for over 10 years (data not shown) (6).

Despite $97 \%$ of FWAs reporting that proper remuneration and workloads are important to them (data not shown) (6), they described dissatisfaction with their lower pay scale, in comparison to HAs.

"The discrimination of salary with the HAs is that they are getting an increment more than us. Some HAs take pride in saying that they work in a higher position than us. Their pride is that they have a higher pay scale grade. Both of us [are] working in the field and doing similar work, why should we face discrimination?" -FWA, FGD

Although at a higher pay grade than FWAs, HAs also expressed discontent with their own pay scale, with some working for decades in the same role without advancement. For FWAs and HAs alike, increases in their pay scales could result in advancements and increase salaries.

"I have been working in this position for almost 30 years. I also had dream[s] of promotion. I cannot quit my job... So, we need promotion."-HA, FGD

High client volumes create an added challenge for FWAs, who are apparently shouldering the burden of persistent $\mathrm{CHW}$ vacancies. High workloads can contribute to poor performance, affecting quality of care. One FWA described assuming additional work beyond prescribed areas due to other $\mathrm{CHW}$ vacancies, leaving her less time for routine household responsibilities:

"As I have [a] large number of service seekers, working beyond my [routine] areas due to vacancies, my hand aches because I have to write all this information. I have to work in the field and write details of 60-70 pregnant women each month... If I had less work or had to write less, I could continue my work willingly and comfortably beside my family work." - FWA, IDI
TABLE 1. FWA SATISFACTION WITH COMPENSATION, INCENTIVES, AND WORKLOAD ( $\mathrm{N}=76)$

\begin{tabular}{|c|c|c|c|c|}
\hline Indicator & $\begin{array}{c}\text { Strongly } \\
\text { dissatisfied } \\
\%\end{array}$ & $\begin{array}{c}\text { Dissatisfied } \\
\%\end{array}$ & $\begin{array}{c}\text { Satisfied } \\
\%\end{array}$ & $\begin{array}{l}\text { Strongly } \\
\text { satisfied } \\
\%\end{array}$ \\
\hline $\begin{array}{l}\text { Amount of } \\
\text { total financial } \\
\text { compensation you } \\
\text { receive }\end{array}$ & 6.6 & 23.7 & 38.2 & 31.6 \\
\hline $\begin{array}{l}\text { Timeliness in } \\
\text { receiving financial } \\
\text { incentives }\end{array}$ & 4.0 & 5.3 & 46.1 & 44.7 \\
\hline $\begin{array}{l}\text { Additional payment } \\
\text { for your work }\end{array}$ & 10.5 & 32.9 & 42.1 & 14.5 \\
\hline $\begin{array}{l}\text { Number of hours } \\
\text { you work in a typical } \\
\text { day }\end{array}$ & 4.0 & 17.1 & 68.4 & 10.5 \\
\hline $\begin{array}{l}\text { Long term job } \\
\text { security }\end{array}$ & 0.0 & 0.0 & 32.9 & 67.1 \\
\hline
\end{tabular}

\section{Lack of promotion opportunities}

FWAs do not feel properly recognized for their work, focused on the lack of a standardized promotion system and little or no opportunities to advance to higher positions. FWA supervisors mentioned the importance of promotion opportunities, especially for FWAs working in the same positions for decades:

\footnotetext{
"There should be a promotion system for FWAs because [the] same position for a long time can cause boredom. I know a worker who has forty years of experience, but she retired at the same post she joined. Now she has no further chance to utilize her experience.... if a worker works for a long time in a specific position, her motivation decreases."-FWA Supervisor, IDI
}

HA supervisors reiterated that some HAs have worked for decades in the same positions, not provided opportunities to advance and attain positions such as Assistant Health Inspectors (AHIs) or Health Inspectors (HIs):

"The promotion process is very complicated. One employee passes 30 or 35 years working for the same post. Very few get the promotion based on the seniority level. The government doesn't determine the promotion based on their eligibility. If they joined the department as an HA, they retire from the same position. They do not get the opportunity to become an AHI or HI. How cruel is this!"-HA Supervisor, IDI

\section{Lack of training opportunities}

This study also reveals varying degrees of training among FWAs, which have effects on health care provision and client quality of care. 
Interviews with FWAs and their supervisors revealed that some FWAs working for decades in Bangladesh's community health system received minimal formal training.

Qualitative findings reveal disagreement among FWAs and their supervisors on the types and frequency of training for FWAs. Some FWAs reported specialized training in areas such as nutrition and adolescent health, in addition to basic training, while other FWAs reported only basic training.

"I had basic training.... It was based [on] one topic family planning methods. Beside this, they also teach on relevant things. But the main training is focused on family planning. That training aids us a lot. We can't do the job if we don't know about it. The training is about the method, advantages, disadvantages, who can take which method, who can't." -FWA, IDI

Family Planning Inspectors (FPIs), supervisors of FWAs, generally concur that trainings do not occur frequently enough, and that older FWAs without any training should be provided opportunities for training.

"The workers we have are working for 30-35 years. They did not receive basic level training. If they could receive at least two [or] three trainings, then they would be more skillful and stimulated. They would be more insightful in their work." -FPI, IDI

HAs involved in focus group discussions (FGDs) also describe insufficient training opportunities. Some HAs, just as FWAs had reported, received no basic training, while some only received a general orientation, and others received basic health training:

"I haven't received any training, only [basic introduction]. I provided the BCG vaccine every year, but I neither have training nor technical rank. In the past, a basic training was given for the new recruits. But for a few years, new recruits have not been receiving any basic training. Trainings on specific topics are available [to some], but this is not enough." - HA, FGD

\section{Importance of client trust in FWAs}

Despite these challenges, FWAs' positive impacts on their communities are evident. Clients express a high degree of trust in them, particularly in their competence and respectful communication (8). Almost $90 \%$ of surveyed clients $(n=1,017)$ believe their FWAs are telling them everything they needed to know about healthrelated problems most or all the time, and $96 \%$ of clients believe their FWAs know as much about a health topic as they should know, most or all of the time (Figure 1).

The majority of survey respondents, 95\%, stated FWAs treat them with respect most or all of the time, $91 \%$ feel better emotionally most or all of the time after talking to a FWA, and almost 97\% stated that the FWA treated them with respect most or all of the time (Figure 1).

\section{FIGURE 1. SAMPLE ITEM FREQUENCIES OF CLIENT TRUST IN FWA HEALTH CARE COMPETENCE AND RESPECTFUL COMMUNICATION $(\mathrm{N}=1,017)$}

All of the time (\%) Most of the time (\%) Less of the time (\%)

How often have you felt the FWA was telling you everything you needed to know about your health-related problems?

(3) How often have you felt the FWA knew as much as she should about a health topic?

How often has the FWA kept what you discussed confidential/private from others in your community? How often has the FWA been an excellent listener?

How often have you felt better (emotionally) after seeing/talking to the FWA?

How often has the FWA treated you with respect?
64.4

10.5

70.2

26.1

54.6

27.0

囚) 


\section{RECOMMENDATIONS AND IMPLICATIONS}

CHW' motivation and satisfaction must be strengthened to elevate their performance and improve community health outcomes. In order to make this a reality, we recommend policy and program stakeholders in Bangladesh:

1. Provide equitable pay scales for both FWAs and HAs to improve satisfaction and respect. Many FWAs indicate dissatisfaction with their compensation and workloads and feel undervalued and not respected because they are paid less than HAs although performing similar duties.

2. Establish a national system for FWA and HA promotion that has systematic performance assessments with key requirements and standards. The WHO recommends governments include "a career ladder to well performing CHWs" in their $\mathrm{CHW}$ program policies (9). Systematic performance assessments can be implemented to assess FWA and $\mathrm{HA}$ eligibility for promotion.

3. Develop formalized and specialized CHW training that provides updates for each CHW every three years. Provide opportunities for CHWs to submit requests for training to program managers. Our study findings show that FWAs and HAs have varying levels of training, with opportunities for refresher and specialized trainings not clearly standardized nor available.

As providers of community-based health information and services, FWAs and HAs in Bangladesh are highly respected and trusted yet face a myriad of challenges that can affect their performance. Providing support and opportunities for advancement will further empower them to fully realize their potential as critical actors within the community health system.

\section{CONTACT}

Sharif Hossain

Principal Investigator

Population Council

sharifhossain@popcouncil.org

Pooja Sripad

Technical Advisor

Population Council

psripad@popcouncil.org

Sarah Kennedy

Project Coordinator

Population Council

skennedy@popcouncil.org

\section{REFERENCES}

1. The World Bank. (2018). Nurses and Midwives (per 1,000 people) Bangladesh. Available from: https://data.worldbank.org/indicator/ SH.MED.NUMW.P3?locations=BD

2. The World Health Organization. (2016). Health Workforce Requirements for Universal Health Coverage and the Sustainable Development Goals.

3. Government of the People's Republic of Bangladesh. (2019) Bangladesh National Strategy for Community Health Workers (20192030).

4. Exemplars in Global Health. (2020). Community Health Workers in Bangladesh. Available from: https://www.exemplars.health/topics/ community-health-workers/bangladesh

5. Hossain S, Sripad P, Zieman B, Roy S, Kennedy S, Hossain I, Bellows B. Measuring quality of care at the community level using the contraceptive method information index plus and client reported experience metrics in Bangladesh. J Glob Health 2021;11:07007.

6. Gottert A, McClair TL, Hossain S, Dakouo SP, Abuya T, Kirk K, Bellows B, Agarwal S, Kennedy S, Warren C, Sripad P. Development and validation of a multi-dimensional scale to assess community health worker motivation. J Glob Health 2021,11:07008.

7. Frontline Health Project. 2020. Frontline Health: Harmonizing metrics, advancing evidence, accelerating policy. Washington, D.C. Population Council. Available from: https://www.popcouncil.org/ uploads/pdfs/2020RH_FrontlineHealthOverviewBrief.pdf

8. Sripad P, McClair TL, Casseus A, Hossain S, Abuya T, Gottert A. Measuring client trust in community health workers: A multicountry validation study. J Glob Health. 2021;11:07009.

9. World Health Organization. WHO guideline on health policy and system support to optimize community health worker programmes. 2018. Available from: https://apps.who.int/iris/bitstream/hand le/10665/275474/9789241550369-eng.pdf

Suggested citation: Frontline Health Project. 2021. Using evidence to advocate for the professional growth of community health workers in Bangladesh. Washington, D.C.: Population Council. 